\title{
Health-related quality of life in obese youth in the lower Mississippi Delta
}

\author{
Wendy L. Ward ${ }^{1 *}$, Judith L. Weber ${ }^{1}$, Jeff Gossett ${ }^{1}$, Pippa Simpson ${ }^{1}$, Margaret L. Bogle ${ }^{2}$, \\ James M. Robbins ${ }^{1}$ \\ ${ }^{1}$ Department of Pediatrics, College of Medicine, Arkansas Children's Hospital, University of Arkansas for Medical Sciences, Little \\ Rock, USA; ${ }^{*}$ Corresponding Author: wward@uams.edu \\ ${ }^{2}$ Agricultural Research Service, United States Department of Agriculture, Little Rock, USA
}

Received 13 April 2012; revised 24 May 2012; accepted 3 June 2012

\section{ABSTRACT}

Objective: Adults and children in rural settings are at greater risk for overweight and obesity than those in urban settings. Multiple studies have suggested that quality of life is lower for obese individuals. This study addresses the association of obesity with health-related Quality of Life (QOL) among youth in the rural Mississippi Delta. Methods: QOL data on children aged 3 - 17 years using the PedsQL were collected as part of a cross-sectional telephone survey in the Delta. Weight was grouped by AAP categorizations as underweight, normal, overweight (85 95th BMI percentile), obese (95 - 97th percentile), and extremely obese (>97th percentile). Results: 437 youth participated. Multiple linear regression models were used to predict PedsQL component scores. Results showed main effects for age $(p=0.006)$, race $(p<0.001)$, and BMI group $(p=0.049)$ on psychosocial QOL. Older children ages 9 - 17, white and black children, and obese or extremely obese children scored lower on psychosocial QOL than younger children, other race, and non-obese. A strong age by weight group interaction $(p=0.014)$ showed that obesity and extreme obesity was associated with lower scores on psychosocial QOL only for older children ages 12 - 17. Conclusions: Investigating the $\mathrm{QOL}$ in this rural community where the majority of adults and children are obese aids in our understanding the relationship between sociocultural factors and HRQOL. In the context of an obese majority obesity and extreme obesity remain important contributions to reduced psychosocial (emotional, social, school performance) quality of life for adolescents but not for younger children).
Keywords: Pediatric Obesity; Overweight; Quality of Life; Rural Health

\section{INTRODUCTION}

Obesity is more prevalent in rural areas than metropolitan ones [1-3], a finding that cannot be explained by demographic factors alone [4] even socioeconomic status [5]. Rural children who were overweight were more likely than urban children to be white, female, live in households $<200 \%$ of the federal poverty level, have no health insurance, have not received preventive health care in the past 12 months, have more medical comorbidities, use a computer for nonschool work $>3$ hours a day, watch television for $>3$ hours a day [1], and lower access to retail food stores [6]. Rural children are thought to share the same "environment" including a complex web of individual, household, social and community factors [7-9] referred to as "contextual obesogenic factors" operating in the rural culture [5].

Obesity in children and adolescents has been associated with significant disturbance in health-related quality of life [10]. However, discrepancies exist between samples. In clinic-based studies, obese youth have lower overall health-related quality of life (HRQOL) than normal weight youth and lower HRQOL in physical, social, school performance, and emotional domains [11]. In contrast, large-scale community samples find BMI is associated with HRQOL but not as strongly or as consistently across communities [12-14]. Social context may help explain these discrepancies, and in fact be a greater predictor of HRQOL in community samples than functional limitation, socioeconomic status, race, gender, or other factors [15].

The present study addresses the association of obesity and HRQOL in among children in the rural region of the Mississippi Delta. The Lower Mississippi Delta region of Arkansas, Louisiana, and Mississippi includes 36 counties bordering or closely contiguous to counties border- 
ing the Mississippi river. The region is predominantly rural [16] and below the poverty level [17]. In this region, there are higher self-reported rates of obesity, hypertension, and diabetes $[18,19]$ and twice the rate of household food insecurity compared to the US population [20]. In essence, we investigated HRQOL in the context of a sociocultural setting where obesity is normative, hypothesizing that because of this setting lower HRQOL would not be found in obese youth. Whether this is true in a culture where surrounding adults and youth are also commonly overweight or obese has yet to be tested, particularly in a rural setting. Because of the large-scale nature of the present study, developmental differences in the relationship between HRQOL and obesity in a rural environment were also explored. We hypothesized that obesity may have a greater impact on psychosocial domains of HRQOL as children age, given that the relationship between obesity and low self-esteem strengthens during adolescence [21].

\section{METHOD}

\subsection{Sample}

Data on HRQOL of obesity youth is available as part of the Delta NIRI Foods of our Delta Survey (FOODS 2000) collected between January and June 2000. FOODS 2000 was a cross-sectional telephone survey of a representative sample of the population 3 years of age and older in 36 counties and parishes in the Lower Mississippi Delta of Arkansas, Louisiana, and Mississippi [19]. The primary focus of this survey was on dietary food intake for the region [22]. This research was reviewed and approved by the institutional review board of each partner university and Westat. Westat (Rockville, MD, USA) conducted participant sampling, interviewer training and telephone interviews for FOODS 2000. Sampling was done using a two stage stratified cluster design, described in detail elsewhere [22]. List-assisted randomdigit dialing methodology was used to select a random sample of eligible blocks of numbers. Training of phone interviewers included home study, demonstration interviews, and interactive lectures and role-playing. Of the 3455 eligible households, 1293 households (37.4\%) refused to participate. This participation rate reflects the increasing difficulty in recruiting participants in scientific surveys, particularly in low-income minority populations [23].

A computer-assisted telephone interview was conducted to determine the eligibility of the household. An eligible household was one that had at least one member aged 18 years or older; the telephone number was not for business use only; and the household was located in 1 of the 18 sampled Delta counties. During this initial interview, information on age, sex, ethnicity of household members, and the presence of children in the household was determined. All members of the household were enumerated and one adult per household was selected randomly using the Kish Tables [24]. One child was selected from single-child households and randomly selected from households with more than one child. A second nonscheduled telephone call was made to households who agreed to participate to collect information regarding dietary intake, height and weight, and child health-related quality of life.

Data on 485 children aged 3 to 17 years were collected in the follow-up interview. Of these, 437 children had complete data for all study variables needed to compute analyses, and these constituted the final sample for these analyses.

\subsection{Measures}

The Pediatric Quality of Life Inventory (Peds QL) version 4.0 is a measure of health-related quality of life for children ages 2 - 18 years old [25]. While the PedsQL was initially designed for various chronic illness pediatric populations, it has been used extensively with obese pediatric subjects to assess quality of life in population-based studies where actual health status other than BMI is unknown [26-28].

The PedsQL consists of 23 items measured on a 5 point Likert scale ranging from "never" to "almost always". The PedsQL can be used to generate a total score and two subscales - psychosocial and physical subscales. The psychosocial subscale includes questions that assess the domains of emotional, social, and academic functioning. Scores were transformed to a 0 to 100 scale so that higher scores indicate better health-related QOL. There are four developmentally appropriate forms: Parent Report for Toddlers (for ages 3 - 4); Parent Report for Young Children (for ages 5 - 8), Child Report with parent assistance as needed (for ages 9 - 11), and Teen Report (ages 12 - 18 years). The content of these parallel forms is identical. The child forms use developmentally appropriate language to allow for differences in cognitive abilities between age groups. Internal consistency reliability for the generic core scales ranges from $\alpha=0.93$ to 0.86 [25]. Test-retest reliability is not applicable as the PedsQL is designed to be sensitive to clinically significant changes in health status. Good content, construct, convergent and discriminant validity have all been reported, along with excellent sensitivity/responsiveness to change [29,30]. The PedsQL is a widely-used measure in studies of pediatric obesity [26-28], therefore no reliability or validity analyses were conducted with this study.

Height and weight were measured by proxy report (ages 3 - 8 years), parent-assisted interview (ages 9 - 11), self-report with adult present for interview (12 - 14), and 
self-report (ages 15 - 17). These measures were used to construct Body Mass Index values. BMI percentiles were calculated from $\mathrm{CDC}$ weight and height norms, adjusted for age (in years) and gender [31]. Obese youth were defined as BMI $\geq 95$ th percentile.

A total of 482 subjects completed the study; 142 toddlers and young children (ages 3 - 4; parents reporting and ages 5 - 8; parents reporting, combined); 79 children (ages 9 - 11; youth reporting); and 218 teenagers (ages 12 - 18; youth reporting). Due to incomplete data, not all subjects were included in analyses (final $n=435$ ). Data were collapsed between toddlers and young children for PEDSQL analyses. Please see Table 1 for demographic characteristics of the sample for which we have complete data.

\section{RESULTS}

\section{Quality of Life Analyses}

Psychosocial scores were differentially associated by age for the BMI percentile categories (underweight, normal, overweight, obese, and extremely obese), as noted in Figure 1.

Multiple linear regression models were used to predict PedsQL Psychosocial composite scores based on BMI percentile (underweight, normal, overweight, obese, and extremely obese), age group ( 3 to 8,9 to 11 , and 12 to 17), race (Caucasian, African American, and "other"), sex, race by sex interaction, and BMI group by age group interaction. Sampling weights were used to adjust for differing probabilities of selection. SUDAAN 10.0 was used for all calculations. Results showed main effects for age, race, and BMI group on psychosocial QOL (See Tables $\mathbf{2}$ and $\mathbf{3}$ for summary of significance of effects in regression models for physical and psychosocial score models). Older children ages 9 - 17, Caucasian and African American children, and obese or extremely obese children scored lower on psychosocial QOL than younger children, other race, and non-obese. A strong age by weight group interaction $(p=0.014)$ showed that obesity and extreme obesity was associated with lower scores on psychosocial QOL only for ages $12-17$.

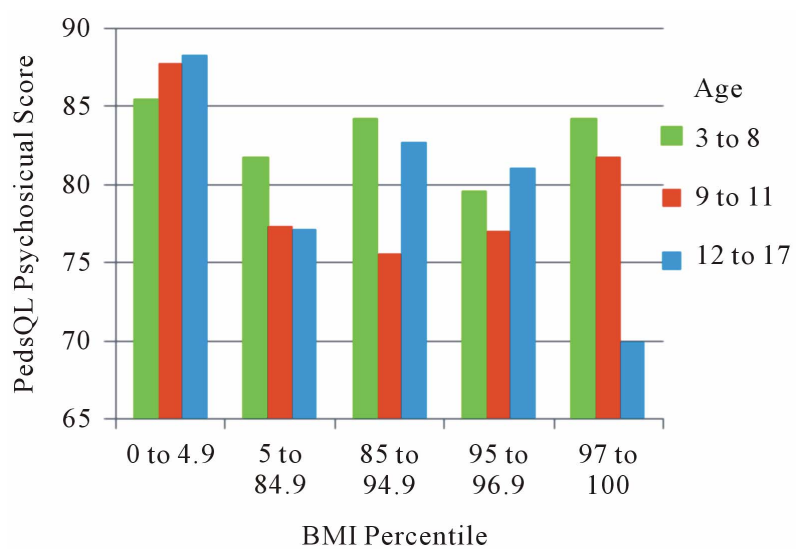

Figure 1. BMI percentile as related to PedsQL psychosocial score in adolescents.

Table 1. Demographic characteristics of sample by BMI percentiles.

\begin{tabular}{|c|c|c|c|c|c|c|}
\hline & Total & Under weight & Normal & Over weight & Obese & Extremely obese \\
\hline BMI percentile range & 0 to 100 & 0 to 4.999 & 5 to 84.999 & 85 to 94.999 & 95 to 96.999 & 97 to 100 \\
\hline Weighted size & 180,486 & 8406 & 79,228 & 29,832 & 16,785 & 46,235 \\
\hline $\mathrm{N}(\%)$ & $435(100 \%)$ & $21(5 \%)$ & $198(44 \%)$ & $81(17 \%)$ & $30(9 \%)$ & $105(26 \%)$ \\
\hline \multicolumn{7}{|l|}{ Sex } \\
\hline Male & $210(100 \%)$ & $15(6 \%)$ & $89(39 \%)$ & $35(16 \%)$ & $17(11 \%)$ & $54(28 \%)$ \\
\hline Female & $225(100 \%)$ & $6(3 \%)$ & $109(49 \%)$ & $46(17 \%)$ & $13(8 \%)$ & $51(23 \%)$ \\
\hline \multicolumn{7}{|l|}{ Race } \\
\hline White & $198(100 \%)$ & $11(6 \%)$ & $92(44 \%)$ & $40(18 \%)$ & $16(12 \%)$ & $39(20 \%)$ \\
\hline Black & $220(100 \%)$ & $10(4 \%)$ & $97(44 \%)$ & $40(16 \%)$ & $14(8 \%)$ & $59(29 \%)$ \\
\hline Other & $17(100 \%)$ & $0(0 \%)$ & $9(38 \%)$ & $1(13 \%)$ & $0(0 \%)$ & $7(49 \%)$ \\
\hline \multicolumn{7}{|l|}{ Age } \\
\hline 3 to 8 & $142(100 \%)$ & $14(9 \%)$ & $41(27 \%)$ & $20(13 \%)$ & $5(5 \%)$ & $62(46 \%)$ \\
\hline 9 to 11 & $77(100 \%)$ & $2(3 \%)$ & $33(41 \%)$ & $20(24 \%)$ & $9(16 \%)$ & $13(17 \%)$ \\
\hline 12 to 17 & $216(100 \%)$ & $5(2 \%)$ & $124(60 \%)$ & $41(16 \%)$ & $16(10 \%)$ & $30(12 \%)$ \\
\hline
\end{tabular}

Note that percentages are calculated using sampling weights. 
Table 2. Summaries of PedsQL subscores by age and BMI group.

\begin{tabular}{|c|c|c|c|c|c|c|c|}
\hline \multirow{2}{*}{ Age group } & \multirow{2}{*}{ BMI group } & \multicolumn{6}{|c|}{ Mean (SE), N } \\
\hline & & Emotional & Physical & Psychosocial & School & Social & Total \\
\hline 03 to 08 & $\begin{array}{l}\text { Underweight } \\
\text { ( } 0 \text { to } 4.999 \text { th) }\end{array}$ & $\begin{array}{c}75.2(4.7) \\
14\end{array}$ & $\begin{array}{c}94.7(1.5) \\
14\end{array}$ & $\begin{array}{c}84.2(2.9) \\
14\end{array}$ & $\begin{array}{c}83.9(4.9) \\
11\end{array}$ & $\begin{array}{c}93.7(2.1) \\
14\end{array}$ & $\begin{array}{c}88.1(2.1) \\
14\end{array}$ \\
\hline 03 to 08 & $\begin{array}{c}\text { Normal } \\
\text { (5th to 84.999th) }\end{array}$ & $\begin{array}{c}76.2(3.4) \\
41\end{array}$ & $\begin{array}{c}92.4(1.8) \\
41\end{array}$ & $\begin{array}{l}81.6(2.0) \\
41\end{array}$ & $\begin{array}{c}81.1(3.9) \\
39\end{array}$ & $\begin{array}{c}88.3(2.1) \\
41\end{array}$ & $\begin{array}{c}85.4(1.6) \\
41\end{array}$ \\
\hline 03 to 08 & $\begin{array}{c}\text { Overweight } \\
\text { (85th to } 94.999 \text { th) }\end{array}$ & $\begin{array}{c}78.7(3.6) \\
20\end{array}$ & $\begin{array}{c}95.2(0.6) \\
20\end{array}$ & $\begin{array}{c}83.5(2.8) \\
20\end{array}$ & $\begin{array}{c}86.8(3.0) \\
19\end{array}$ & $\begin{array}{c}85.4(3.1) \\
20\end{array}$ & $\begin{array}{c}87.6(1.8) \\
20\end{array}$ \\
\hline 03 to 08 & $\begin{array}{c}\text { Obese } \\
\text { (95th to } 96.999 \text { th) }\end{array}$ & $\begin{array}{c}80.1(7.9) \\
5\end{array}$ & $\begin{array}{c}91.5(1.7) \\
5\end{array}$ & $\begin{array}{c}79.4(5.7) \\
5\end{array}$ & $\begin{array}{c}67.8(5.9) \\
4\end{array}$ & $\begin{array}{c}90.1(6.7) \\
5\end{array}$ & $\begin{array}{c}83.6(4.1) \\
5\end{array}$ \\
\hline 03 to 08 & $\begin{array}{c}\text { Ext Obese } \\
\text { (97th to 100th) }\end{array}$ & $\begin{array}{c}80.4(1.6) \\
\quad 62\end{array}$ & $\begin{array}{c}92.6(1.1) \\
62\end{array}$ & $\begin{array}{c}84.1(1.4) \\
62\end{array}$ & $\begin{array}{c}82.9(2.1) \\
60\end{array}$ & $\begin{array}{c}89.4(1.6) \\
62\end{array}$ & $\begin{array}{c}87.2(1.1) \\
62\end{array}$ \\
\hline 09 to 11 & $\begin{array}{l}\text { Underweight } \\
\text { ( } 0 \text { to } 4.999 \text { th) }\end{array}$ & $\begin{array}{c}86.0(9.3) \\
2\end{array}$ & $\begin{array}{c}97.5(3.9) \\
2\end{array}$ & $\begin{array}{c}88.7(8.3) \\
2\end{array}$ & $\begin{array}{c}80.0(15.6) \\
2\end{array}$ & $\begin{array}{c}100.0(0.0) \\
2\end{array}$ & $\begin{array}{c}91.7(4.1) \\
2\end{array}$ \\
\hline 09 to 11 & $\begin{array}{c}\text { Normal } \\
\text { (5th to } 84.999 \text { th) }\end{array}$ & $\begin{array}{c}71.1(3.8) \\
33\end{array}$ & $\begin{array}{c}85.9(2.7) \\
33\end{array}$ & $\begin{array}{c}77.3(3.0) \\
33\end{array}$ & $\begin{array}{c}78.6(2.2) \\
33\end{array}$ & $\begin{array}{c}82.1(4.5) \\
33\end{array}$ & $\begin{array}{c}80.3(2.7) \\
33\end{array}$ \\
\hline 09 to 11 & $\begin{array}{c}\text { Overweight } \\
\text { (85th to } 94.999 \text { th) }\end{array}$ & $\begin{array}{c}67.9(6.2) \\
20\end{array}$ & $\begin{array}{c}89.0(3.2) \\
20\end{array}$ & $\begin{array}{c}76.2(3.4) \\
20\end{array}$ & $\begin{array}{c}75.5(5.2) \\
20\end{array}$ & $\begin{array}{c}83.9(6.8) \\
20\end{array}$ & $\begin{array}{c}80.6(2.4) \\
20\end{array}$ \\
\hline 09 to 11 & $\begin{array}{c}\text { Obese } \\
\text { (95th to 96.999th) }\end{array}$ & $\begin{array}{c}73.3(4.8) \\
9\end{array}$ & $\begin{array}{c}79.7(5.6) \\
9\end{array}$ & $\begin{array}{c}77.1(4.3) \\
9\end{array}$ & $\begin{array}{c}78.7(5.2) \\
9\end{array}$ & $\begin{array}{c}79.3(5.0) \\
9\end{array}$ & $\begin{array}{c}78.0(4.5) \\
9\end{array}$ \\
\hline 09 to 11 & $\begin{array}{c}\text { Ext Obese } \\
\text { (97th to 100th) }\end{array}$ & $\begin{array}{c}81.4(5.9) \\
13\end{array}$ & $\begin{array}{c}91.6(3.9) \\
13\end{array}$ & $\begin{array}{c}82.0(2.1) \\
13\end{array}$ & $\begin{array}{c}78.7(3.8) \\
13\end{array}$ & $\begin{array}{c}86.0(3.8) \\
13\end{array}$ & $\begin{array}{c}85.4(2.4) \\
13\end{array}$ \\
\hline 12 to 17 & $\begin{array}{l}\text { Underweight } \\
\text { (0 to } 4.999 \text { th) }\end{array}$ & $\begin{array}{c}83.3(6.4) \\
5\end{array}$ & $\begin{array}{c}93.1(1.6) \\
5\end{array}$ & $\begin{array}{c}87.4(4.2) \\
5\end{array}$ & $\begin{array}{c}84.4(7.0) \\
5\end{array}$ & $\begin{array}{c}94.8(1.4) \\
5\end{array}$ & $\begin{array}{c}89.4(3.2) \\
5\end{array}$ \\
\hline 12 to 17 & $\begin{array}{c}\text { Normal } \\
\text { (5th to 84.999th) }\end{array}$ & $\begin{array}{c}70.5(2.0) \\
123\end{array}$ & $\begin{array}{c}87.3(1.1) \\
124\end{array}$ & $\begin{array}{c}77.3(1.4) \\
123\end{array}$ & $\begin{array}{c}73.6(1.8) \\
122\end{array}$ & $\begin{array}{c}87.3(1.5) \\
124\end{array}$ & $\begin{array}{c}80.7(1.1) \\
124\end{array}$ \\
\hline 12 to 17 & $\begin{array}{c}\text { Overweight } \\
\text { (85th to } 94.999 \text { th) }\end{array}$ & $\begin{array}{c}76.9(3.3) \\
41\end{array}$ & $\begin{array}{c}87.8(2.1) \\
41\end{array}$ & $\begin{array}{c}81.9(2.0) \\
41\end{array}$ & $\begin{array}{c}78.1(2.5) \\
41\end{array}$ & $\begin{array}{c}90.8(1.9) \\
41\end{array}$ & $\begin{array}{c}84.0(2.0) \\
41\end{array}$ \\
\hline 12 to 17 & $\begin{array}{c}\text { Obese } \\
\text { (95th to 96.999th) }\end{array}$ & $\begin{array}{c}73.6(4.9) \\
16\end{array}$ & $\begin{array}{c}92.7(1.8) \\
16\end{array}$ & $\begin{array}{c}79.9(1.8) \\
16\end{array}$ & $\begin{array}{c}78.9(2.6) \\
16\end{array}$ & $\begin{array}{c}87.2(2.1) \\
16\end{array}$ & $\begin{array}{c}84.4(1.4) \\
16\end{array}$ \\
\hline 12 to 17 & $\begin{array}{l}\text { Ext Obese } \\
\text { (97th to 100th) }\end{array}$ & $\begin{array}{c}66.8(3.1) \\
30\end{array}$ & $\begin{array}{c}89.1(1.9) \\
30\end{array}$ & $\begin{array}{c}71.4(2.7) \\
30\end{array}$ & $\begin{array}{c}67.1(2.9) \\
30\end{array}$ & $\begin{array}{c}80.4(3.7) \\
30\end{array}$ & $\begin{array}{c}77.6(1.5) \\
30\end{array}$ \\
\hline
\end{tabular}

Note: The PedsQL has a total score and four subscales: Emotional, Physical, School, and Social. The Psychosocial subscale is a combination of Emotional, School, and Social subscales and is commonly used in QOL research in comparison with Physical.

Similar analyses were computed to predict the PedsQL Physical functioning score. Results showed similar effects with two exceptions. First, there was a main effect for gender with girls having lower physical functioning scores than boys. There were lower scores on physical functioning for both $9-11$ and $12-17$ age groups for obesity and extreme obesity.

\section{DISCUSSION}

This study investigated the relationship between HRQOL and obesity in a society where obesity is normative and commonplace. Contrary to hypotheses that HRQOL would be minimally affected by weight status in this obesogenic setting, results suggest there are still negative HRQOL effects especially for older youth and those with greater BMI. In fact, older children ages 9 17, white and black children, and obese or extremely obese children scored lower on psychosocial QOL than younger children, other race, and non-obese. In fact, obesity and extreme obesity remain important contributions to reduced psychosocial (emotional, social, school performance) quality of life for adolescents.

For Physical QOL, results were similar with two exceptions. Over the entire sample, girls had lower physical functioning scores than boys. For those in the obese and extremely obese categories, kids older than 9 had lower scores then those ages 3 - 8 .

The increased risk of obese teenagers for lower QOL (both psychosocial-related and physical-related QOL) is 
Table 3. Overall ANOVA for psychosocial and physical functioning scores.

\begin{tabular}{ccc}
\hline Effect & $\begin{array}{c}\text { Psychosocial } \\
\text { F (Df) }\end{array}$ & $\begin{array}{c}\text { Physical } \\
\text { F (Df) } \\
\text { p-value }\end{array}$ \\
\hline Age_(avg over BMI) & $5.57(2)$ & $7.61(2)$ \\
& 0.006 & 0.0011 \\
Race_-(avg over sex $)$ & $14.55(2)$ & $5.21(2)$ \\
& $<0.0001$ & 0.0082 \\
Sex_-(avg over race) & $0.01(1)$ & $8.40(1)$ \\
& 0.9081 & 0.0052 \\
BMI_grp_(avg over age) & $2.53(4)$ & $5.22(4)$ \\
& 0.0493 & 0.0011 \\
Race * Sex & $2.26(2)$ & $1.18(2)$ \\
& 0.1126 & 0.3136 \\
Age * BMIgrp & $3.19(8)$ & $2.55(8)$ \\
& 0.0044 & 0.0183
\end{tabular}

Effect of BMI group at each age group

$\begin{array}{ccc}\text { BMI grp -ages } 3 \text { to } 8 & 0.54(4) & 1.44(4) \\ & 0.7038 & 0.2321 \\ \text { BMI grp - age } 9 \text { to } 11 & 1.11(4) & 5.01(4) \\ & 0.3592 & 0.0015 \\ \text { BMI grp —age } 12 \text { to } 17 & 5.04(4) & 8.35(4) \\ & 0.0014 & <0.0001\end{array}$

Note: The PedsQL has a total score and four subscales: Emotional, Physical, School, and Social. The Psychosocial subscale is a combination of Emotional, School, and Social subscales and is commonly used in QOL research in comparison with Physical. BMI grp refers to the following percentile classifications: Underweight (0 to 4.9999th), Normal (5th to 84.99999th), Overweight (85th to 94.999 th), Obese (95th to 96.9999th), and Extremely Obese (97th to 100th).

noteworthy. Developmentally, adolescence is a time for emerging self-image and self-esteem and it is possible that the increased pressure toward social acceptance and perceived inability to meet those perceptions are leading to social difficulties and dissatisfaction among obese teens [32], including lower perceived competence in physical appearance and peer engagement [33].

More research is needed to assess HRQOL across a variety of sociocultural settings and identify key risk factors in rural settings with significant health disparities. Toward that end, longitudinal data is needed to further illustrate developmental issues in HRQOL and the processes involved in the emerging psychosocial and physical dissatisfaction.

The present study addressed QOL in an at-risk population with high rates of obesity across ages. Participation in the phone survey was high, however it is unclear whether there are differences among respondents and nonrespondents that would limit the generalizability of the findings to the entire Delta youth population. Further, it is unclear whether these results are generalizable to other at-risk populations who may differ in geographical location, culture, language, etc. Future research is needed to assess generalizability to other populations. Further, this study used developmentally appropriate versions of the PedsQL to assess HRQOL at different ages and used either self-report or parent proxy assessments at various ages. While the content is parallel and the PedsQL is widely used in this manner, comparative results should be interpreted cautiously as the different results may have been influenced by the different versions administered to the different age groups (and the parent report versus self-report distinction that occurs in younger versus older children). One additional concern might be the appropriateness of parent proxy of an internal concept like quality of life especially in toddlers and young children who may not be able to articulate these concerns. However, parent proxy reports are available for preschool youth regarding many functional and psychosocial measures (see [34] for a review) including three parent proxy measures of quality of life (Infant and Toddler Quality of Life Questionnaire, Netherlands Office of Prevention Assessment of Preschool Quality of Life, and PedsQL). Specifically, a review of the reliability and validity of the PedsQL parent proxy for the toddlers and young children versions (parent proxy for ages $2-4$ and 5 - 7) suggests this instrument distinguishes between healthy children and children with special needs, has been translated into multiple languages with similar reliability/validity, is responsive to clinical change over time, and can distinguish disease severity [34]. Further, a large sample study of reliability and validity of parent proxy on the PedsQL supports the feasibility, reliability, and validity of parent proxy for ages 2 - 16 on the PedsQL.

A broader issue should be considered regarding assessment of health-related quality of life in obese youthregarding whether obesity is considered a disease state and whether a health-related quality of life measure (rather than a general quality of life measure) ought to be considered. Obesity is clearly linked to metabolic and cardiovascular risk [35] but obesity is not a disease state per se. However, researchers and clinicians generally consider obesity to be a health condition if not a disease state $[35,36]$ and a public health concern [36,37], and as such health-related quality of life assessment would seem appropriate. However, additional aspects of psychosocial functioning could also be considered worthy of assessment and future research may wish to consider assessment of depression, social anxiety, and low self-esteem, as well as general measures of quality of life to further understand psychosocial functioning in obese youth.

These results may have implications for treating obese youth. First, younger obese youth may see little physical or psychosocial impact on their functioning and thus no impairment in quality of life. If that is the case, they may have lower motivation toward changing food choice 
habits or physical activity. There may be little motivation to change when they look like and behave like many of their peers and the adults around them. For adolescents, the emerging social issues might yield to greater motivation toward changing behaviors that would result in successful weight management. Conversely, the resulting dissatisfaction in the teenage years may provide a context of helplessness and hopelessness that impedes successful treatment efforts. Treatment success has been documented with family-based cognitive behavioral treatment on health-related quality of life in childhood obesity [38] and successful improvement in weight status has been shown to have a positive impact on health-related QOL in obese youth [39].

\section{ACKNOWLEDGEMENTS}

We would like to acknowledge the USDA for funding the data collection for this project (58-6251-8-039).

\section{REFERENCES}

[1] Lutfiyya, M.N., Lipsky, M.S., Wisdom-Behounek, J. and Inpanbutr-Martinkus, M. (2007) Is rural residency a risk factor for overweight and obesity for US children? Obesity, 15, 2348-2356. doi:10.1038/oby.2007.278

[2] Gamm, L.D., Huchison, L.L., Dabney, B.J. and Dorsey, A.M. (2010) Rural healthy people. A companion document to health people 2010 vols. 1-3. A\&M University System Health Services Center School of Rural Public Health, Southwest Rural Health Research Center 2003, College Stations.

[3] Pearson, T.A. and Lewis, C. (1998) Rural epidemiology: Insights from a rural population laboratory. American Journal of Epidemiology, 148, 949-957. doi:10.1093/oxfordjournals.aje.a009571

[4] Davis, C.L., Flickinger, B., Moore, D., Bassali, R., DomelBaxter, S. and Yin, Z. (2005) Prevalence of cardiovascular risk factors in school children in a rural Georgia community. American Journal of the Medical Sciences, 330, 53-59. doi:10.1097/00000441-200508000-00001

[5] Neovius, M. and Rasmussen, F. (2008) Place of residence and obesity in 1,578,694 young Swedish men between 1969 and 2005. Obesity, 16, 671-676. doi:10.1038/oby.2007.115

[6] Schafft, K.W., Jensen, E.B. and Hinrichs, C.C. (2009) Food deserts and overweight schoolchildren: Evidence from Pennsylvania. Rural Sociology, 74, 153-177. doi:10.1111/j.1549-0831.2009.tb00387.x

[7] Eichner, J.E., Moore, W.E., Perveen, G., Kobza, C.E., Abbott, K.E. and Stephens, A.L. (2007) Overweight and obesity in an ethnically diverse rural school district: The healthy kids project. Obesity, 16, 501-504. doi:10.1038/oby.2007.60

[8] Hill, J.O. and Trowbridge, F.L. (1998) The causes and health consequences of obesity in children and adolescents. Pediatrics, 101, 570-574.

\section{doi:10.1542/peds.101.3.570}

[9] Reidpath, D.D., Burns, C., Garrard, J., Mahoney, M. and Townsend, M. (2002) An ecological study of the relationship between social and environmental determinants of obesity. Health and Place, 8, 141-145. doi:10.1016/S1353-8292(01)00028-4

[10] Schwimmer, J.B., Burwinkle, T.M. and Varni, J.W. (2003) Health-related quality of life of severely obese children and adolescents. Journal of the American Medical Association, 289, 1813-1819. doi:10.1001/jama.289.14.1813

[11] Pinhas-Hamiel, O., Singer, S., Pilpel, N., Fradkin, A., Modan, D. and Reichman, B. (2006) Health-related quality of life among children and adolescents: associations with obesity. International Journal of Obesity, 30, 267272. doi:10.1038/sj.ijo.0803107

[12] Swallen, K.C., Reither, E.N., Haas, S.A. and Meier, A.M. (2005) Overweight obesity and health-related quality of life among adolescents: The national longitudinal study of adolescent health. Pediatrics, 115, 340-347. doi:10.1542/peds.2004-0678

[13] Williams, J., Wake, M., Hesketh, K., Maher, E. and Waters, E. (2005) Health-related quality of life of overweight and obese children. Journal of the American Medical Association, 293, 70-76. doi:10.1001/jama.293.1.70

[14] Arif, A.A. and Rohrer, J.E. (2006) The relationship between obesity hyperglycemia symptoms and health-related quality of life among Hispanic and non-Hispanic white children and adolescents. BMC Family Practice, 7, 3. doi:10.1186/1471-2296-7-3

[15] Flodmark, C.E. (2005) The happy obese child. International Journal of Obesity, 2, S31-S33. doi:10.1038/sj.ijo.0803060

[16] United States Department of Agriculture (USDA) (2005) Measuring rurality: Rural-urban continuum codes. Economic Research Service editor. www.ers.usda.gov/briefing/UrbCon/

[17] Thorton, A. (1997) Demographic social and economic characteristics. In: Harrison, G., Ed., Lower Mississippi Delta Nutrition Intervention Research Consortium editors. Nutrition and Health Status in the Lower Mississippi Delta of Arkansas, Louisiana and Mississippi: A Review of Existing Data, Westat, Rockville, 9-23.

[18] Smith, J., Lensing, S. and Horton, J.A. (1999) Prevalence of self-reported nutrition-related health problems in the Lower Mississippi Delta. American Journal of Public Health, 89, 1418-1421. doi:10.2105/AJPH.89.9.1418

[19] Lower Mississippi Delta Nutrition Intervention Research Consortium (2004) Self-reported health of residents of the Mississippi Delta. Journal of Health Care for the Poor and Underserved, 15, 645-662. doi:10.1353/hpu.2004.0056

[20] Stuff, J.E., Horton, J.A. and Bogle, M.L. (2004) High prevalence of food insecurity and hunger in households in the rural lower Mississippi Delta. The Journal of Rural Health, 20, 173-180. doi:10.1111/j.1748-0361.2004.tb00025.x

[21] French, S.A. Story, M. and Perry, C.L. (1995) Self-esteem and obesity in children and adolescents: A literature 
review. Obesity Research, 3, 479-490.

[22] Champagne, D.M., Bogle, M.L., McGee, B.B., Yadrick, K., Allen, H.R. and Kramer, T.R. (2004) Dietary intake in the lower Mississippi Delta region: Results from the foods of our Delta study. Journal of the American Dietetic Association, 104, 199-207. doi:10.1016/j.jada.2003.11.011

[23] Stein, A.D., Lederman, R.I. and Shea, S. (1993) The behavioral risk factor system questionnaire: Reliability in a state wide system. American Journal of Public Health, 83, 1768-1772. doi:10.2105/AJPH.83.12.1768

[24] Kish, L. (1965) Survey Sampling. John Wiley and Sons, Inc., New York.

[25] Varni, J.W., Seid, M. and Rode, C.A. (1999) The PedsQL: Measurement model for the pediatric quality of life inventory. Medical Care, 37, 126-139. doi:10.1097/00005650-199902000-00003

[26] Keating, C., Moodie, M. and Swinburn, B. (2011) The health-related quality of life of overweight and obese adolescents - A study measuring body mass index and adolescent-reported perceptions. International Journal of Obesity, 6, 434-441.

[27] Williams, J., Canterford, L., Hesketh, K., Hardy, P., Waters, E., Patton, G. and Wake, M. (2011) Changes in body mass index and health related quality of life from childhood to adolescence. International Journal of Obesity, 6 , 442-448.

[28] Wake, M., Canterford, L., Patton, G., Hesketh, K., Hardy, P., Williams, J., Waters, E. and Carlin, J. (2010) Comorbidities of overweight/obesity experienced in adolescence: Longitudinal study. Archives of Disease in Childhood, 95, 162-168.

[29] Varni, J.W., Seid, M., Knight, T.S., Uzark, K. and Szer, I.S. (2002) The Peds QL (TM) 4.0 generic core scales: Sensitivity, responsiveness, and impact on clinical decision-making. Journal of Behavioral Medicine, 25, 175193. doi:10.1023/A:1014836921812

[30] Varni, J.W., Burwinkle, T.M. and Seid, M. (2006) The Peds QL ${ }^{\mathrm{TM}} 4.0$ as a school population health measure: Feasibility, reliability, and validity. Quality of Life Research, 15, 203-215. $\underline{\text { doi: } 10.1007 / \mathrm{s} 11136-005-1388-\mathrm{z}}$
[31] Center for Disease Control (CDC) (2005) Overweight and obesity: Defining overweight and obesity. US Department of Health and Human Services. http//www.cdc.gov/nccdphp/dnpa/obesity/defining.htm

[32] Friedman, M.A. and Brownell, K.D. (1995) Psychological correlates of obesity: moving to the next research generation. Psychological Bulletin, 117, 3-20. doi:10.1037/0033-2909.117.1.3

[33] Franklin, J., Denyer, G., Steinbeck, K.S., Caterson, I.D. and Hill, A.J. (2006) Obesity and risk for low self-esteem: A statewide study of Australian children. Pediatrics, 118, 2481-2487. doi:10.1542/peds.2006-0511

[34] Msall, M. (2005) Measuring functional skills in preschool children at risk for neurodevelopmental disabilities. Mental Retardation and Developmental Disabilities Research Reviews, 11, 263-273. doi:10.1002/mrdd.20073

[35] Must, A., Spadano, J., Coakley, E.H., Field, A.E., Colditz, G. and Dietz, W.H. (1999) The disease burden associated with overweight and obesity. Journal of the American Medical Association, 282, 1523-1529. doi:10.1001/jama.282.16.1523

[36] Ogden, C.L., Carroll, M.D., Curtin, L.R., McDowell, M.A., Tabak, C.J. and Flegal, K.M. (2006) Prevalence of overweight and obesity in the United States, 1999-2004. Journal of the American Medical Association, 295, 15491555. doi:10.1001/jama.295.13.1549

[37] Manson, J.E., Skerrett, P.J., Greenland, P. and Vanltallie, T.B. (2004) The escalating pandemics of obesity and sedentary lifestyle. A call to action for clinicians. Archives of Internal Medicine, 163, 249-253. doi:10.1001/archinte.164.3.249

[38] Vos, R., Huisman, S., Houdijk, E., PiJl, H. and Wit, J. (2011) The effect of family-based multidisciplinary cognitive behavioral treatment on health-related quality of life in childhood obesity. Quality of Life Research, 12, 110.

[39] Wille, N., Bullinger, M., Holl, R., Hoffmeister, U., Mann, R., Goldapp, C., Reinehr, T. and Westenhöfer, J. (2010) Health-related quality of life in overweight and obese youths: Results of a multicenter study. Health and Quality of Life Outcomes, 8, 36. doi:10.1186/1477-7525-8-36 